\title{
EXTRATOS VEGETAIS NO CONTROLE DA MOSCA-BRANCA EM MELANCIA
}

\author{
D. K. P. NERI ${ }^{1}$, M. V. P. FREITAS ${ }^{2}$, G. B. GÓES ${ }^{3}$ \\ Instituto Federal de Educação, Ciência e Tecnologia do Rio Grande do Norte ${ }^{1,2}$ \\ Instituto Federal de Educação, Ciência e Tecnologia da Paraíba ${ }^{3}$ \\ ORCID ID: http://orcid.org/0000-0003-2722-3987 \\ danila.neri@ifrn.edu.br ${ }^{1}$
}

DOI: $10.15628 /$ holos. 2020.7740

\section{RESUMO}

Tendo uma produção anual cada vez maior, principalmente no Nordeste, onde há condições climáticas favoráveis, a cultura da melancia é uma das principais geradoras de divisas e empregos diretos e indiretos no Rio Grande do Norte. No entanto, os ataques de pragas estão entre os principais fatores limitantes da produção, tendo seu controle com base na utilização de produtos químicos, que além de aumentar o custo de produção geram acúmulo de resíduos químicos nos frutos. Para contornar este problema é necessário criar novas alternativas para o manejo de pragas, em especial a mosca-branca que se destaca como uma das principais. Em um cenário onde pesquisas relacionadas aos inseticidas de origem vegetal abrem perspectivas e espaço para sua utilização no controle de pragas, o presente trabalho teve como objetivo avaliar o efeito de extratos vegetais no controle da mosca-branca em melancia. Foram realizados testes de livre escolha para alimentação e oviposição utilizando-se quatro extratos aquosos (nim, tiririca, pimentão e sorgo) e testemunha (água), com quatro repetições. Os tratamentos foram dispostos ao acaso em gaiolas formando uma arena cujo meio foi liberado a praga. Concluiu-se que as plantas de melancia pulverizadas com extratos de nim foram menos atrativas à mosca-branca, tanto para alimentação quanto para oviposição.

PALAVRAS-CHAVE: Cucurbitaceea, Bemisia tabaci biótipo B, controle natural.

\section{VEGETABLE EXTRACTS IN THE CONTROL OF THE WHITE FLY IN WATERMELON}

\begin{abstract}
With an increasing annual production, mainly in the Northeast, where there are favorable climatic conditions, the watermelon culture is one of the main generators of foreign exchange and direct and indirect jobs in Rio Grande do Norte. However, pest attacks are among the main factors limiting production, being controlled based on the use of chemicals, which in addition to increasing production costs generate accumulation of chemical residues in the fruits. To overcome this problem, it is necessary to create new alternatives for pest management, especially the whitefly that stands out as one of the main ones. In a scenario where research
\end{abstract}

related to plant-based insecticides opens up perspectives and space for its use in pest control, the present study aimed to evaluate the effect of plant extracts in the control of watermelon whiteflies. Free choice tests for feeding and oviposition were performed using four aqueous extracts (neem, nutsedge, pepper and sorghum) and control (water), with four replicates. The treatments were randomly arranged in cages, forming an arena in which the pest was released. It was concluded that watermelon plants sprayed with neem extracts were less attractive to whiteflies, both for food and for oviposition.

KEYWORDS: Curcubitaceae, Bemisia tabaci biotype B, natural control

HOLOS, Ano 36, v.4, e7740, 2020 


\section{INTRODUÇÃO}

A melancia (Citrullus lanatus Thunb.) pertence à família Cucurbitaceae, sendo bastante produzida e consumida em várias partes do mundo. O Brasil ocupa a quarta posição em produção deste fruto no mundo, com 2,08 milhões de toneladas, atrás da China (70,0 milhões de toneladas), Irã (3,8 milhões de toneladas) e Turquia (4,04 milhões de toneladas) (FAOSTAT, 2016).

No Nordeste brasileiro a alta luminosidade, baixos índices pluviométricos e baixa umidade relativa do ar, são fatores ambientais que favorecem a produção desta cultura o ano inteiro e, consequentemente, potencializa o aumento das exportações e garante expressão econômica e social, pois são gerados empregos diretos nos vários setores da cadeia produtiva (transporte, comercialização, venda de insumos e outros) (MENDONÇA JÚNIOR, 2015).

No Estado do Rio Grande do Norte, a melancia ainda é muito cultivada por pequenos agricultores apenas no período das chuvas em sistema de sequeiro (MEDEIROS, 2015). No entanto, as condições ambientais favoráveis no estado fizeram com que muitos produtores investissem no cultivo irrigado, tornando a exploração da cultura muito tecnificada, principalmente quando destinada ao mercado externo (OLIVEIRA, 2013).

Diante das exigências do mercado, o cultivo da melancia passou a demandar elevado investimento, principalmente com o uso de fertilizantes e aplicação de agrotóxicos como fungicidas e inseticidas. De acordo com Medeiros (2015), anualmente, somente em inseticidas na cultura da melancia chegam a responder por mais de $16 \%$ dos gastos operacionais totais, fato que onera bastante o custo de produção e preocupa os produtores e a comunidade científica, que tenta encontrar alternativas com menor impacto ambiental e que apresentem efetividade comprovada.

Dentre os principais problemas fitossanitários, a mosca-branca (Bemisia tabaci) se destaca como uma das pragas mais importantes da agricultura mundial. Esta praga recebe atenção especial em função de sua vasta quantidade de plantas hospedeiras, que inclui a melancia, levando essa cucurbitaceae a grandes percas, em caso de incidência deste inseto (QUINTELA, 2015).

Além de causar prejuízos diretos, como à sucção de seiva e injeção de toxinas, a moscabranca pode proporcionar grande queda na produtividade em virtude dos danos indiretos, como a excreção de substâncias açucaradas durante a alimentação, que favorece a formação da fumagina e diminui os processos de fotossíntese pela planta, e a disseminação de vírus, já que esta praga é vetora de diversos vírus de importância econômica (SANTANA, 2015).

O manejo da mosca-branca tornou-se grande desafio aos agricultores, uma vez que esta praga apresenta rápida capacidade de desenvolver resistência as diferentes classes de inseticidas (SILVA et al., 2012). 
Devido ao acúmulo de produtos químicos no meio ambiente, o uso de substâncias alelopáticas ou repelentes, surgem como ferramenta complementar junto aos métodos convencionais de controle de pragas na agricultura. Estas substâncias se destacam por serem de baixo custo, não poluentes e não requerem uso de equipamentos sofisticados para seu uso (OLIVEIRA et al., 2015). Sendo assim, o presente trabalho objetivou avaliar o efeito de extratos vegetais no controle de mosca-branca.

\section{REVISÃO DE LITERATURA}

\subsection{Características da cultura da melancia}

A melancia [Citrullus lanatus (Thunb.) Matsum \& Nakai] pertencente à família das Cucurbitaceae, sendo uma planta anual, herbácea, de hábito de crescimento rasteiro, com ramificações sarmentosas e pubescentes, apresenta caule constituído de ramos primários e secundários, as folhas têm disposição alternada apresentando limbo com contorno triangular, possuem gavinhas, e um sistema radicular concentrando-se até $30 \mathrm{~cm}$ abaixo da superfície do solo (DIAS; REZENDE, 2010).

A melancia, é uma hortaliça nativa da África, considerada uma das mais importantes produzidas e comercializadas no Brasil, cujo cultivo é realizado de maneira intensiva (OLIVEIRA et al., 2014). A produção mundial de melancia é estimada em 109.278,714 toneladas (FAOSTAT, 2018). Segundo o instituto Brasileiro de geografia e estatística (IBGE, 2016) a produção desta cucurbitácea atingiu 2.090,432 toneladas no ano de 2016. Os maiores produtores, são os estados do Rio Grande Do Sul e Goiás, enquanto no Nordeste, os estados da Bahia e Rio Grande do Norte são os maiores, com produção estimada de 212,48 e 121,047 toneladas, respectivamente (SALES, 2015). Sendo que no Estado do Rio Grande do Norte, a melancia está como principal produto agrícola da pauta de exportação.

A cultura da melancia, quando comparada com outras hortaliças, possui um fácil manejo e baixo custo de produção, fato que facilita para que pequenos agricultores possam cultiva-la. No Rio Grande do Norte, essa cucurbitácea é cultivada principalmente pela agricultura de sequeiro e em regiões irrigadas, especialmente nos municípios da Serra do Mel, de Mossoró e Baraúnas (MEDEIROS, 2015).

Referindo-se aos fatores que podem provocar percas à esta cultura, é perceptível que os danos de pragas se destacam por comprometerem uma boa produção. Por exemplo, a moscabranca que é citada como uma praga importante e de alto potencial causador de perdas na produção da melancia, principalmente pela transmissão de vírus que provocam doenças nas plantas (LIMA, 2017). 


\subsection{Danos e importância econômica de Bemisia tabaci biótipo $b$}

As moscas-brancas são insetos sugadores muito pequenos, pertencentes à ordem Hemiptera e família Aleyrodidae, tendo a espécie Bemisia tabaci, como a mais frequente em cultivos de hortaliças no Brasil. O ciclo biológico é formado por ovo, ninfa e adulto, sendo que geralmente os indivíduos se fixam na face inferior das folhas (MICHEREFF FILHO; LIMA, 2016).

A B. tabaci foi descrita há mais de 100 anos, e desde então se tornou uma das pragas mais importantes do mundo na agricultura tropical e subtropical, pois a mesma apresenta grande capacidade de adaptação a novas plantas hospedeiras e regiões geográficas. O transporte internacional de material vegetal e de pessoas, bem como o aumento da produção e das áreas agrícolas, tem contribuído para a sua propagação geográfica. No Brasil, após introdução do biótipo $B$, a propagação e o aumento no tamanho da população de mosca-branca foram favorecidos (QUINTELA, 2015).

Dessa forma, a mosca-branca é considerada uma importante praga da agricultura em regiões tropicais e subtropicais, visto que esta espécie é bastante temida pelos agricultores, que pela experiência e convívio no campo, chegam a sofrer grandes quedas na produção devido às perdas e danos provocados por esta praga nas culturas trabalhadas em campo (IMBRAHIM, 2015).

A mosca-branca pode causar diversos prejuízos, dentre eles estão os diretos, relacionados à sucção de seiva e injeção de toxinas, responsável por provocar o amadurecimento irregular dos frutos, que se tornam internamente esbranquiçados e com aspecto esponjoso. E os indiretos, com a liberação de uma substância açucarada (honeydew), que provoca a proliferação do fungo Capnodium sp. (fumagina) na superfície de folhas, o que diminui a área fotossintética da planta e, consequentemente, sua produtividade (CARVALHO et al., 2015) ou através da trasmissão de viroses, que é o dano mais sério causado por esse inseto (SILVA et al., 2017; HOELHERT et al., 2017). As doenças causadas por vírus em vegetais são responsáveis por altos prejuízos à agricultura brasileira, isto porque uma infestação pode causar visíveis danos na estrutura das plantas, afetando negativamente a produção total (NARITA, 2016). São relatados casos com perdas de até $100 \%$ em decorrência de doenças como o Begomovirus e Carlavirus, transmitidas por B. tabaci (LIMA, 2017).

É notável por parte dos agricultores a alta incidência desta praga nas lavouras e áreas de cultivo. Fato que incentiva a necessidade de repensar algumas atitudes, pois o desequilíbrio populacional da mosca-branca preocupa e vem levando a cada ano, parte da rentabilidade e aumentando cada vez mais os custos de produção (SANTOS, 2016). Isto em longo prazo, pode representar sérios prejuízos na cadeia produtiva de culturas como a melancia que sofre grandes perdas devido ao ataque desta praga. 
A principal forma de controle de B. tabacié por meio de produtos químicos, que geralmente são utilizadas em quantidades exageradas e de modo irracional, causando prejuízos, principalmente relacionados à contaminação ambiental, afetando a saúde dos produtores e consumidores. Além disso, a mosca-branca apresenta rápida capacidade de desenvolver resistência às diferentes classes de inseticidas, tornando o manejo da mesma um grande desafio aos agricultores (SILVA et al., 2012)

Rodrigues (2014) explica que a mosca-branca apresenta alta taxa de fecundidade o que representa um fator negativo para o seu combate, mas além disso ela tem como característica a partenogênese, ou seja, uma fêmea sobrevivente à uma aplicação de inseticida será capaz de produzir clones que vão manter possíveis genes de resistência a produtos químicos, o que facilita o estabelecimento da população da praga.

Diante disso, o efeito repelente de alguns extratos pode ser utilizado como instrumento que venha a complementar os métodos convencionais, tendo em vista que produtos como os produtos naturais, representam um novo caminho no controle de insetos e microrganismos na agricultura. Tornando comum a tomada de iniciativas que busquem a produção agrícola de forma sustentável, o que de fato é benéfico e necessário (SILVA; CALEMAN, 2015).

\subsection{Efeito de extratos vegetais sobre a mosca-branca}

O manejo mais comum no controle da mosca-branca é baseado pelo método químico com o emprego de inseticidas sintéticos. Porém, há relatos de resistência do inseto a inseticidas de diversos grupos químicos disponíveis no mercado, o que pode ser evidenciado pelo aumento dos casos de surtos registrados nas regiões produtoras (SANTOS, 2017).

O uso de extratos vegetais vem sendo adotados e, tem sido comprovados seus efeitos positivos no controle de pragas e doenças. Isso se deve, especialmente, à eficácia do seu princípio ativo que causa poucas perturbações ao meio ambiente (LEAL et al., 2016).

Nesse contexto, tem-se intensificado as pesquisas visando inserir novas alternativas de controle no manejo de insetos-praga na agricultura, como por exemplo, uso de inseticidas naturais de origem botânica, com destaque aos derivados do nim (Azadirachta indica) (COSTA et al., 2016).

O nim, Azadicacta indica A. Juss (Meliaceae), é a planta inseticida mais conhecida e utilizada, e algumas formulações à base de extratos orgânicos (enriquecidos ou não), de óleos brutos ou de limonoides purificados de suas sementes encontram-se disponíveis no mercado de diferentes países (CARVALHO et al., 2015). 
O nim apresenta substâncias biologicamente ativas capazes de produzir efeito repelente no manejo da mosca-branca. No entanto, o método a ser utilizado é muito importante para o sucesso do resultado, tendo em vista a importância de aspectos como a dosagem, a época de aplicação, a quantidade e a intensidade de produto a ser aplicado (SANTANA et al., 2016).

O que de fato representa mais uma boa característica dos extratos vegetais provenientes do nim, é que além de sua capacidade de repelir pragas indesejáveis na cultura, ainda apresenta efeito deletério sobre mosca-branca, principalmente nas fases de ninfa em que ela é pouco móvel. Peixoto e Boiça Junior (2017), ao avaliarem o efeito de óleo de nim no feijão, constataram que este produto reduziu a oviposição da mosca-branca além de propiciar alta mortalidade de ninfas.

Muitas espécies vegetais com possibilidades de apresentar efeito alelopático contra pragas, ainda não são muito trabalhadas e pouco se encontra a respeito das mesmas para essa finalidade, dentre elas está a tiririca (Cyperus rotundus). Barbosa et al. (2007), em experimento sob condições de laboratório, obtiveram resultados satisfatórios no uso do extrato aquoso de tiririca em maiores concentrações para mortalidade de Diabrotica speciosa. Acrescentam ainda que por ser uma planta espontânea, a tiririca é facilmente encontrada, tornando-se uma boa opção para ser usada como alternativa de controle de pragas em sistemas agroecológicos.

Vieira Júnior et al. (2017), tiveram 48 extratos aquosos de pimentas do gênero Capsicum como objeto de análise, para o combate de fitopatógenos, em que algumas espécies foram capazes de controlar todos os desafiantes, mostrando que esses extratos possuem compostos bioativos possíveis de controlar fungos fitopatogênicos.

É notável que, para a maioria das pesquisas que visam encontrar meios alternativos no combate das pragas voltadas ao uso de extratos vegetais, plantas do grupo das gramíneas pouco aparecem, fato que serve como motivação para a exploração de novas espécies com possível potencial alelopático. Correia, Centurion e Alves (2005), estudaram o efeito alelopático de extratos aquosos de sorgo sobre a germinação e o desenvolvimento de soja, isto por afirmarem que estudos conduzidos em laboratório ou em condições de campo demonstram o potencial alelopático da espécie Sorghum bicolor L., seja inibindo a germinação e o desenvolvimento de plantas daninhas ou até mesmo de plantas cultivadas em sucessão. Porém, estudos com o uso dessa espécie no combate de pragas ainda é escasso.

\section{MATERIAIS E MÉTODOS}

O experimento foi conduzido em casa de vegetação na área experimental do Instituto Federal de Educação, Ciência e Tecnologia do Rio Grande do Norte, Campus Apodi, no mês de março de 2017. Seguindo a metodologia adaptada de Neri et al. (2006). 
A cultivar utilizada foi Crimson Sweet $\left(\operatorname{Top~Seed~}^{\circledR}\right.$ ) que apresenta elevada produtividade e performance, a qual foi semeada primeiramente em bandejas de isopor com 128 células, com substrato comercial Plantimax ${ }^{\circledR}$. Após cinco dias da emergência, essas mudas foram transplantadas para vasos plásticos com capacidade de $500 \mathrm{~mL}$ de substrato contendo solo e esterco bovino na proporção de 2:1, respectivamente.

Adultos de mosca-branca foram coletados inicialmente no campo, em um plantio de melancia localizado na chapada do Apodi, em seguida foram levadas para gaiolas aonde permaneceram em plantas de tomate, alface e abóbora plantadas em vasos até serem utilizados nos testes de livre escolha.

O delineamento utilizado foi em blocos ao acaso contendo cinco tratamentos (extratos aquosos e testemunha) e quatro repetições. Os tratamentos utilizados foram os extratos aquosos de nim (Azadirachta indica), tiririca (Cyperus rotundus), pimentão (Capsicum annuum) e sorgo (Sorghum bicolor), além da testemunha a qual utilizou-se somente água. As folhas utilizadas na obtenção dos extratos aquosos foram coletadas no campo agrícola do IFRN - Campus Apodi, em seguida, trituradas com água e armazenadas durante $24 \mathrm{~h}$, depois filtrada com tecido fino ("voil"), em seguida acrescentou-se água até obter a concentração de $5 \%$.

Os experimentos foram dvididos em dois testes: um com teste de escolha para alimentação pelos adultos de mosca-branca e outro com teste de escolha para ovoposição. No primeiro, aplicou-se os tratamentos pulverizando as folhas das plantas na face inferior e superior, em seguida, cinco plantas, sendo uma de cada tratamento, foram dispostas ao acaso dentro de gaiolas retangulares $(0,7 \times 0,6 \times 0,5 \mathrm{~m}$ de altura) recobertas com tecido de voil. Posteriormente, no centro de cada gaiola foram liberados 50 adultos de mosca-branca, provenientes da criação de manutenção e capturados com o uso do "sugador". Depois da liberação as avaliações do número de adultos presentes em cada planta consistiram na contagem visual do número de indivíduos em cada folha após 1, 24, 48 e $72 \mathrm{~h}$ da instalação. Ao todo foram quatro gaiolas que ficaram dispostas casualmente sobre bancadas de madeira em casa-de-vegetação, sendo cada gaiola uma repetição.

Já o teste com chance de escolha para oviposição, as plantas dos diferentes tratamentos também foram dispostas em círculo e no centro foram liberados 50 adultos das moscas-branca. Porém, somente após 72 horas fez-se o recolhimento de duas folhas de cada planta (tratamento) e realizou-se a contagem dos ovos com auxílio de um microscópio estereoscópico. A contagem foi realizada na face inferior da folha, numa área de um disco com $2,8 \mathrm{~cm}$ de diâmetro.

Os dados obtidos foram submetidos à análise de variância, sendo as médias transformadas em $v x+1$ e comparadas pelo teste de Tukey a $5 \%$ de probabilidade. 


\section{RESULTADOS E DISCUSSÃO}

No teste de escolha para alimentação pelos adultos de mosca-branca, o número de insetos nas plantas de melancia foi significativamente diferente entre os tratamentos nas avaliações realizadas após 24 e 48 horas. Já nas avaliações realizadas até 1 h e depois de 72 h não houve diferença estatística no número de insetos observados entre os tratamentos (Tabela 1).

Tabela 1: Número de insetos adultos de mosca-branca em plantas de melancia (média \pm erro padrão) em diferentes tempos. IFRN - Campus Apodi, 2018.

\begin{tabular}{lcccc}
\hline \multirow{2}{*}{ TRATAMENTOS } & \multicolumn{4}{c}{ NÚMERO DE ADULTOS NOS DIFERENTES TEMPOS } \\
\cline { 2 - 5 } & $\mathbf{1 h}$ & $\mathbf{2 4 h}$ & $\mathbf{4 8 h}$ & $\mathbf{7 2 h}$ \\
\hline Extrato de Nim & $1,00 \pm 1,15 \mathrm{a}$ & $1,00 \pm 0,81 \mathrm{a}$ & $1,75 \pm 2,21 \mathrm{a}$ & $1,50 \pm 1,00 \mathrm{a}$ \\
Extrato de tiririca & $5,75 \pm 5,12 \mathrm{a}$ & $5,00 \pm 2,7 \mathrm{~b}$ & $6,25 \pm 4,19 \mathrm{~b}$ & $8,25 \pm 5,31 \mathrm{a}$ \\
Extrato de Pimentão & $2,25 \pm 2,87 \mathrm{a}$ & $8,00 \pm 5,83 \mathrm{~b}$ & $5,25 \pm 5,44 \mathrm{~b}$ & $5,00 \pm 5,71 \mathrm{a}$ \\
Extrato de Sorgo & $3,75 \pm 2,75 \mathrm{a}$ & $4,00 \pm 2,16 \mathrm{~b}$ & $4,75 \pm 4,27 \mathrm{~b}$ & $4,50 \pm 3,87 \mathrm{a}$ \\
Testemunha & $4,50 \pm 3,41 \mathrm{a}$ & $10,25 \pm 4,19 \mathrm{c}$ & $12,75 \pm 6,85 \mathrm{c}$ & $12,50 \pm 7,00 \mathrm{a}$ \\
\hline Fc & 1,117 & 4,455 & 2,669 & 2,962 \\
\hline $\mathrm{p}$ & $0,393^{\mathrm{ns}}$ & $0,019 * *$ & $0,084^{*}$ & $0,065^{*}$ \\
\hline CV (\%) & 41,85 & 28,33 & 36,79 & 36,19
\end{tabular}

Letras seguidas de mesma letra minúscula na coluna não diferem estatisticamente entre si pelo teste de Tukey a $10 \%$ de probabilidade. Fc, valor do teste $\mathrm{F}$ para o número de moscas-brancas adultas; $\mathrm{P}$, probabilidade de significância devido ao acaso; CV (\%), coeficiente de variação em percentagem; Nota: **, *; níveis de significância à $5 \%$ e $10 \%$, respectivamente. Fonte: Próprios autores, 2018.

A ausência de diferença estatística entre os tratamentos na avaliação realizada uma hora depois da liberação das moscas, pode ser explicada devido ao curto período de tempo de exposição das plantas para escolha dos insetos, que possivelmente ainda estavam selecionando a melhor planta para se estabelecerem.

Já nas avaliações realizadas as 24 e 48 horas após a liberação das moscas, foi notória a diferença entre os tratamentos, pois nas plantas tratadas com extrato de nim havia baixa quantidade de moscas (Tabela 1), enquanto que nos demais tratamentos o número de moscas só foi inferior à testemunha, que apresentou o maior número de insetos nas folhas.

Os resultados observados no teste de repelência são semelhantes aos obtidos por Silva et al. (2012), que verificaram que as plantas de abobrinha pulverizadas com extratos provenientes de $A$. indica foram repelentes a mosca-branca, comparativamente às plantas pulverizadas com água 
destilada. Lima et al. (2011), utilizando óleo de nim também observaram que o extrato apresenta eficiência no controle da B. tabaci em tomate.

Vale ressaltar que na avaliação realizada 72 horas após a liberação dos insetos, os resultados foram estatisticamente semelhantes (Tabela 1). Isso provavelmente aconteceu por conta da não persistência do efeito repelente dos extratos, e, portanto, a partir daí as moscas escolheram qualquer planta para se fixarem. Situação semelhante também ocorreu nos testes de Silva et al. (2012), em que após 48 horas da aplicação dos extratos, não observaram diferenças estatísticas entre os tratamentos. Os autores explicam que provavelmente os extratos aquosos tenham reduzido seus efeitos devido sofreram oxidação e isso diminui a bioatividade sobre a moscabranca.

As plantas tratadas com extrato de nim foram as que apresentaram menor quantidade de ovos de mosca-branca (Tabela 2). Os demais tratamentos foram semelhantes entre si e a folhas que receberam apenas água (testemunha) apresentaram o maior número de ovos.

Tabela 2: Número de ovos de mosca-branca presentes em folhas de melancia (média \pm erro padrão) após 72 h de exposição. IFRN - campus Apodi, 2018.

\begin{tabular}{l|c}
\hline TRATAMENTOS & NUMERO DE OVOS \\
\hline Extrato de Nim & $1,75 \pm 2,06 \mathrm{a}$ \\
Extrato de tiririca & $23,00 \pm 22,01 \mathrm{~b}$ \\
Extrato de Pimentão & $33,00 \pm 56,08 \mathrm{~b}$ \\
Extrato de Sorgo & $28,25 \pm 28,87 \mathrm{~b}$ \\
Testemunha & $82,25 \pm 51,14 \mathrm{c}$ \\
\hline Fc & 3,899 \\
\hline $\mathrm{p}$ & $0,030 * *$ \\
\hline $\mathrm{CV}(\%)$ & 53,14 \\
\hline
\end{tabular}

Letras seguidas de mesma letra minúscula na coluna não diferem estatisticamente entre si pelo teste de Tukey a $5 \%$ de probabilidade. Fc, valor do teste $\mathrm{F}$ para o número de moscas-brancas adultas; $\mathrm{P}$, probabilidade de significância devido ao acaso; CV (\%), coeficiente de variação em percentagem; Nota: ${ }^{* *}$, nível de significância à $5 \%$. Fonte: Próprios autores, 2018.

Trabalhos semelhantes também constataram que em folhas pulverizadas com $A$. indica, os insetos não apresentaram preferência por oviposição (SILVA et al., 2012; ZACHÉ, 2012). Em folhas de feijoeiro, produtos comerciais a base de nim, fumo, extratos aquosos de folha de nim e arruda, reduziram significativamente a oviposição de $B$. tabaci, em relação à testemunha. Neste mesmo 
trabalho, os os autores verificaram que o número de ovos nas folhas diminuiu, conforme o aumento da concentração dos produtos (QUINTELA \& PINHEIRO, 2009). A fase de ovo desse inseto é a mais difícil de ser controlada, no entanto, em ensaio realizado com aplicação de óleo de nim, constatou-se uma tendência de maior inviabilidade dos ovos de mosca-branca, indicando que o tratamento com este produto pode ser a melhor alternativa (TAVARES et al., 2010).

No geral, os tratamentos à base de folhas de $A$. Indica foram os mais repelentes aos adultos da mosca-branca, podendo ser recomendados como alternativa no manejo desta praga em melancia. Sendo necessário ressaltar que, no caso específico da mosca-branca em melancia, a baixa atratividade é de grande importância, uma vez que, ao diminuir a quantidade de insetos na planta, minimiza-se também os dados diretos e os indiretos, como a transmissão de doenças virais.

\section{CONCLUSÃO}

Plantas de melancia tratadas com extrato aquoso de nim a 5\% apresentaram efeito repelente tanto para alimentação como para oviposição de adultos de mosca-branca.

\section{REFERÊNCIAS}

BARBOSA, F. S., LEITE, G. L. D., PAULINO, M. A. O., GUILHERME, D. O., MAIA, J. T. L. S., FERNANDES, R. C., COSTA, C. A. (2007, outubro). Utilização de extratos de tiririca no controle de Diabrotica speciosa. Rev. Bras. de Agroecologia, 2 (2), 764-767.

CARVALHO, S. S., VENDRAMIM, J. D., SÁ, I. C. G., SILVA, M. F. G. F., RIBEIRO, L. P., FORIM, M. R. (2015, julho). Efeito inseticida sistêmico de nanoformulações à base de nim sobre Bemisia tabaci (Hemiptera: Aleyrodidae) biótipo B em tomateiro. Bragantia, 74 (3), 298-306.

CORREIA, N. M., CENTURION, M. A. P. C., ALVES, P. L. A. (2005, maio). Influência de extratos aquosos de sorgo sobre a germinação e o desenvolvimento de plântulas de soja. Ciência Rural, 35 (3), 498-503.

COSTA, E. M., TORRES, S. B., FERREIRA, R. R., SILVA, F. G., ARAUJO, E. L. (2016/ abril). Extrato aquoso de sementes de nim no controle de Liriomyza sativae (Diptera: Agromyzidae) em meloeiro. Revista Ciência Agronômica, 47 (2), 401-406.

DIAS, R. C. S.; REZENDE, G. M. (2010/ agosto). Sistema de Produção de Melancia: socioeconomia. Embrapa. Recuperado em 26 março, 2018, de https://sistemasdeproducao.cnptia.embrapa.br/FontesHTML/Melancia/SistemaProducaoM elancia/socioeconomia.htm\#topo 
FAOSTAT. (2018). Recuperado em 27 março, 2018, de http://www.fao.org/statistics/databases/en/

IBRAHIM, A. B. (2015). Resistência a mosca branca (Bemisia tabaci) em plantas transgênicas expressando siRNA do gene de uma v-ATPase. Tese de Doutorado, Universidade de Brasília, Brasília, DF, Brasil.

INSTITUTO BRASILEIRO DE GEOGRAFIA E ESTATÍSTICA. (2016). Produção agrícola municipal: Produtos das lavouras temporárias e permanentes. Recuperado em 10 abril, 2018, de https://sidra.ibge.gov.br/tabela/5457\#resultado

LEAL, T. T. B., OliVEIRA, F. É. R., OliVEIRA, V. C., GONZALEZ, S. D. P., SILVA, R. M. S. REIS, A. S., SILVA, R. (2016/ abril). Extrato de pimenta dioica no controle in vitro de Aspergillus niger, patógeno da cultura do sisal. Magistra, 28, 2, 254-260.

LIMA, B. M. F. V., MOREIRA, J. O. T., PINTO, H. C. S. (2011/ outubro). Avaliação de extratos vegetais no controle de mosca branca em tomate. Revista Caatinga, 4, (24), 36-42.

LIMA, C. H. O. (2017). Sistema de tomada de decisão de controle de Bemisia tabaci em cultivos de melancia. Tese de Doutorado, Universidade Federal do Tocantins, Gurupi, TO, Brasil.

MEDEIROS, R. V. (2015). Caracterização Morfológica, Molecular E Reação De Acessos De Melancia A Didymella Bryoniae. Dissertação de Mestrado, Universidade Federal Rural do Semi-Árido, Mossoró, RN, Brasil.

MENDONÇA JÚNIOR, A. F. (2015). Crescimento, produção e qualidade de melão e melancia cultivadas sob extrato de alga Ascophyllum nodosum (I.). Dissertação de Pós-Graduação, Universidade Federal Rural do Semi-Árido, Mossoró, RN, Brasil.

MICHEREFF F. M., LIMA, M. F. (2016). Manejo da mosca-branca, de geminivírus e crinivírus na cultura da batata. Comunicado Técnico, Brasília, mai. Recuperado em 30 março, 2018, de https://edisciplinas.usp.br/pluginfile.php/3597934/mod_resource/content/0/Circular\%20E mbrapa-Manejo\%20de\%20mosca-branca\%20e\%20viroses\%20em\%20batata.pdf

NARITA, J. P. Z. (2016). Aspectos biológicos e comportamentais de Bemisia tabaci biótipo B (Genn.) (Hemiptera: Aleyrodidae) em genótipos de tomateiro e sua relação com o Tomato severe rugose vírus. Dissertação de Mestrado, Universidade de São Paulo, Piracicaba, SP, Brasil.

NERI, D. K. P., GÓES, G. B., MARACAJÁ, P. B., MEDEIROS, D. C., NUNES, G. H. S. (2006). Efeito do extrato aquoso de nim sobre Bemisia tabaci biótipo b (Gennadius) (Hemiptera: Aleyrodidae). Revista Verde, 1, (2), 48-53.

OLIVEIRA, J. B. (2013). Desempenho de cultivares de melancia em diferentes épocas de plantio, no município de Mossoró- RN. Tese de Pós-Graduação, Universidade Federal Rural do SemiÁrido, Mossoró, RN, Brasil. 
OLIVEIRA, J. S. PEIXOTO, C.P; POELKING, V.G.C., ALMEIDA, A. T. (2015). Avaliação de extratos das espécies Helianthus annuus, Brachiaria brizanthae Sorghum bicolor com potencial alelopático para uso como herbicida natural. Rev. bras. plantas med., 17, (3).

OliVEIRA, L. M., CAVALhEIRO, V. B. D., MORES, D. M., TILMANN, M. Â. A., \& SCHUCH, L. O. B. (2014). Medição do CO2 como método alternativo para a diferenciação do vigor de lotes de sementes de melancia. Ciência Rural, 45, (4), 606-611.

PEIXOTO, M. L., BOIÇA JUNIOR, A. L. (2017/ julho). Associação entre genótipos de feijoeiro, silício e nim no controle da mosca-branca Bemisia tabaci (Gennadius, 1889) biótipo B (Hemiptera: Aleyrodidae). Rev. Ceres, 64, (4), 376-383.

QUINTELA, E. D.; PINHEIRO, P. V. (2009). Redução da oviposição de Bemisia tabaci (Genn.) Biótipo $B$ (Hemiptera: Aleyrodidae) em folhas de feijoeiro tratadas com extratos botânicos. BioAssay, 4 (8), 1-10.

QUINTELA, E. D. (2015). Nova mosca-branca: ainda mais resistente. Recuperado em 27 março, 2018, de http://www.revistacampoenegocios.com.br/nova-mosca-branca-ainda-maisresistente/

RODRIGUES, P. (2014). A mosca dos vírus. In: VIEIRA, Jairo Vidal (Org.). Hortaliças em revista. p. 69. Brasília, DF.

SALES, V. F. S. (2015). Efeito da aplicação pré-colheita de bioestimulante e espaçamento de plantio na produção, qualidade e conservação de melancia. Tese de Doutorado, Universidade Federal Rural do Semi-Árido, Mossoró, RN, Brasil.

SANTANA, M. V. (2015). Danos do Cowpea mild mottle virus (CPMMV) e de mosca-branca (Bemisia tabaci Genn.) no feijoeiro-comum geneticamente modificado resistente ao Bean golden mosaic virus. Dissertação de Mestrado, Universidade Federal de Goiás, Goiânia, GO, Brasil.

SANTANA, J. L., SANTOS NETO, J. E., SILVA, T. S., COSTA, D. S., OLIVEIRA, C. S. (2016). Avaliação do manejo das hortas agroecológicas tratadas com bioinseticidas. Cadernos Macambira, 1, (2).

SANTOS, A. P. (2016). Soluções de Combate à Mosca Branca. Recuperado em 27 março, 2018, de http://www.pioneersementes.com.br/blog/77/solucoes-de-combate-a-mosca-branca

SANTOS, J. B. (2017). Ecologia da mosca-branca, Bemisia tabaci (Gennadius) e de seus parasitóides em soja. Tese de Doutorado, Universidade Federal de Goiás, Goiânia, GO, Brasil.

SILVA, A. G., BOIÇA JUNIOR, A. L. B., SOUZA, B. H. S., COSTA, E. N., HOELHERT, J. S., ALMEIDA, A. M., SANTOS, L. B. (2017). Mosca-branca, Bemisia tabaci (Genn.) (Hemiptera: Aleyrodidae) em feijoeiro: Características gerais, bioecologia e métodos de controle. Entomo Brasilis, 10, (1), 1-8. 
SILVA, D. B., CALEMAN, S. M. Q. (2015). Produção agrícola sustentável: Análise de um sistema de produção de hortaliças em Mato Grosso do Sul. Revista Eletrônica, 17, (1).

SILVA, J. P. G. F., ZACHÉ, R. R. C., BALDIN, E. L. L., OLIVEIRA, F. B., VALTAPELI, E. R. (2012). Repelência e deterrência na oviposição de Bemisia tabaci biótipo B pelo uso de extratos vegetais em Cucurbita pepo L. Revista Brasileira de Plantas Medicinais, 14 (1), 76-83.

TAVARES, A. P. M., SALLES, R. F. M., OBRZUT, V. V. (2010/ abril). Efeito ovicida de nim, citronela e sassafrás sobre a mosca branca Bemisia spp. Rev. Acad., Ciênc. Agrár. Ambient, 8, (2), 153159.

VIEIRA JÚNIOR, J. R., FERNANDES, C. F., SIMONE, C. S., FREIRE, T. C., FONSECA, A. S. (2017). Extratos de espécies de Capsicum no controle in vitro de patógenos de importância agrícola. Enciclopédia biosfera: Centro Científico Conhecer, 14 (25), 673- 866.

ZACHÉ, R. R. C. (2012) Resistência de genótipos de Cucurbita spp. à Bemisia tabaci biótipo b (hemiptera: Aleyrodidae) e interação com extratos vegetais. Tese de doutorado, Faculdade de Ciências Agronômicas da Universidade Estadual Paulista, Botucatu, SP, Brasil.

\section{COMO CITAR ESTE ARTIGO:}

Neri, D.K.P., Freitas, M.V.P., Góes, G.B.(2020). Extratos vegetais no controle da mosca-branca em melancia. Holos, 36(4), 1-14.

\section{SOBRE OS AUTORES}

\section{DANILA KELLY PEREIRA NERI}

Professora do Instituto Federal de Educação, Ciência e Tecnologia do Rio Grande do Norte (IFRN); Doutora em Agronomia (Entomologia) pela Universidade de Lavras.

E-mail: danila.neri@ifrn.edu.br

ORCID ID: http://orcid.org/0000-0003-2722-3987

\section{MOISES VICTOR PRAXEDES DE FREITAS}

Estudante do Instituto Federal de Educação, Ciência e Tecnologia do Rio Grande do Norte (IFRN).

E-mail: moisespraxedes40@hotmail.com

ORCID ID: http://orcid.org/0000-0002-7528-6096

\section{GILTON BEZERRA DE GÓES}

Professor do Instituto Federal de Educação, Ciência e Tecnologia da Paraíba (IFPB); Mestre em Agronomia (Ciência do Solo) pela Universidade Federal Rural do Semi-Árido (UFERSA).

E-mail: giltonbezerra@yahoo.com.br

ORCID ID: http://orcid.org/0000-0002-6926-7083

Editor(a) Responsável: Francinaide de Lima Silva Nascimento

Pareceristas Ad Hoc: Marcia Nozaki e Jaconias Lima Neto 


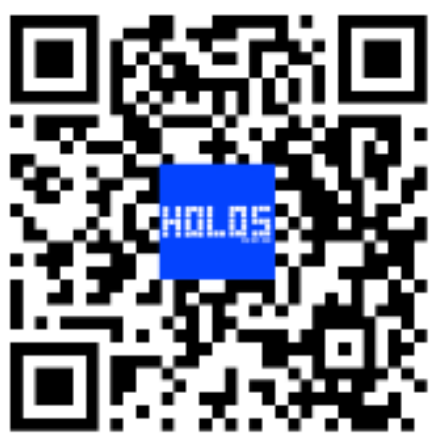

Recebido: 13 de setembro de 2018 Aceito: 24 de junho de 2020

Publicado: 01 de julho de 2020 